\title{
Numerical Study of the Fatigue Crack in Welded Beam-To-Column Connection Using Cohesive Zone Model
}

\author{
C. Lequesne ${ }^{1}$, A. Plumier ${ }^{1}$, H. Degee ${ }^{1}$ and A.M. Habraken ${ }^{1}$ \\ ${ }^{I} M \& S$ Department, University of Liege, 1 Chemin des Chevreuils, 4000 Liege, Belgium
}

\begin{abstract}
The fatigue behaviour of the welded beam-to-column connections of steel moment resisting frame in seismic area must be evaluated. The cohesive zone model is an efficient solution to study such connections by finite elements. It respects the energetic conservation and avoids numerical issues. A three-dimensional cohesive zone model element has been implemented in the home made finite element code Lagamine [1]. It is coupled with the fatigue continuum damage model of Lemaitre and Chaboche [2]. The cohesive parameters are identified by the inverse method applied on a three points bending test modelling.
\end{abstract}

Keywords: Cohesive Zone Model, Fatigue, Welding

\section{Introduction}

Some brittle cracks appeared in weld beam-to-column connections in steel moment frame buildings during the Northridge and Kobe earthquakes [3]. Since then it is required to compute the crack strength of these structures. The aim of the present study is the development of a finite element tool which models the crack process during cyclic tests. In this problem, the structure is submitted to high levels of inelastic strains and cyclic loadings. The crack process is simulated by cohesive zone model. This model conserves the energy and the ellipticity of the equations so that problems of mesh dependence are avoided. It simulates the initiation and the propagation of crack. Finally, it can be coupled with fatigue models [4]. A three dimensional crack element is developed in Lagamine code. Three points are developed in this paper. Firstly the cohesive zone model is explained. Secondly, the three dimensional crack element is presented. Finally the method used to determine the cohesive parameters is described.

\section{Cohesive Zone Model}

Dugdale and Barenblatt [5,6], explained that a zone behind the crack tip (cf. Fig. 1) has a different behaviour from the bulk material due to micro damage phenomena such as micro void nucleation in steel. This zone may be modelled by two elements linked by cohesive stresses and initially superposed. The degradation is then described by the constitutive law relating the separation between the two surfaces and the evolution of the cohesive stress (cf. Fig. 2). First the cohesive stresses increase with the separation until reaching a maximal value (in Fig. 1 : point A to B). Then they decrease due to irreversible damages and become null after complete rupture (in Fig. 1 : point B to C). The area under the curves in Fig. 2 represents the required energy to generate the two new surfaces and the micro damage phenomena. This model describes both normal (mode I) and shear cracking (mode II) (cf. Fig. 1).

Fig. 1: Presentation of the Cohesive Zone in mode I and mode II and definition of the cohesive stress components and the separation components
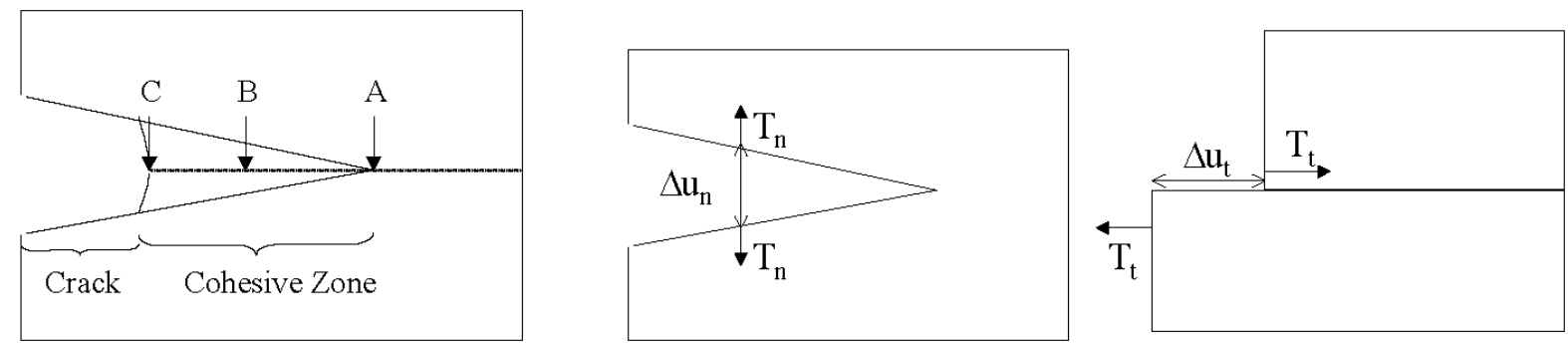
One defines the separation vector, $\Delta \underline{\mathrm{u}}$, and a stress vector, $\underline{T}_{\mathrm{CZ}}$, with their respective components, $\Delta \mathrm{u}_{\mathrm{n}}, \Delta \mathrm{u}_{\mathrm{t}}, \mathrm{T}_{\mathrm{n}}$ and $\mathrm{T}_{\mathrm{t}}$ in normal and tangent directions (cf. equation (3) and Fig. 1). The chosen model is the Xu and Needleman one's [7] that already proved its efficiency for cracking in steel.

$$
\begin{aligned}
& \mathrm{T}_{\mathrm{n}}=-\frac{\phi_{\mathrm{n}}}{\delta_{\mathrm{n}}} \exp \left(-\frac{\Delta \mathrm{u}_{\mathrm{n}}}{\delta_{\mathrm{n}}}\right)\left\{\frac{\Delta \mathrm{u}_{\mathrm{n}}}{\delta_{\mathrm{n}}} \exp \left(-\frac{\Delta \mathrm{u}_{\mathrm{t}}^{2}}{\delta_{\mathrm{t}}^{2}}\right)+\left(\frac{1-\mathrm{q}}{\mathrm{r}-1}\right)\left(1-\exp \left(-\frac{\Delta \mathrm{u}_{\mathrm{t}}^{2}}{\delta_{\mathrm{t}}^{2}}\right)\right)\left(\mathrm{r}-\frac{\Delta \mathrm{u}_{\mathrm{n}}}{\delta_{\mathrm{n}}}\right)\right\} \\
& \mathrm{T}_{\mathrm{t}}=\left(\frac{\phi_{\mathrm{n}}}{\delta_{\mathrm{n}}}\right)\left(\frac{2 \delta_{\mathrm{n}}}{\delta_{\mathrm{t}}}\right) \frac{\Delta \mathrm{u}_{\mathrm{t}}}{\delta_{\mathrm{t}}}\left\{\mathrm{q}+\left(\frac{\Delta \mathrm{u}_{\mathrm{n}}}{\delta_{\mathrm{n}}}\right)\left[\frac{\mathrm{r}-\mathrm{q}}{\mathrm{r}-1}\right]\right\} \exp \left(-\frac{\Delta \mathrm{u}_{\mathrm{n}}}{\delta_{\mathrm{n}}}\right) \exp \left(-\frac{\Delta \mathrm{u}_{\mathrm{t}}^{2}}{\delta^{2}}\right) \\
& \Delta \underline{\mathrm{u}}=\left|\begin{array}{l}
\Delta u_{n} \\
\Delta u_{t}
\end{array} \quad \underline{T}_{C Z}=\right| \begin{array}{l}
T_{n} \\
T_{t}
\end{array}
\end{aligned}
$$

Material constants: $\phi_{t}=\sqrt{\frac{e}{2}} \tau_{\max } \delta_{t} ; \phi_{n}=\sigma_{\max } e \delta_{n} ; r=\frac{\Delta u_{n}^{*}}{\delta_{n}} ; q=\frac{\phi_{t}}{\phi_{n}} ; e=\exp (1)$

$\sigma_{\max }$ and $\tau_{\max }$ are the maximal normal and shear stresses. $\delta_{\mathrm{n}}$ and $\delta_{\mathrm{t}}$ are the separations when respectively the normal or the shear stress is maximal. $\phi_{\mathrm{n}}$ and $\phi_{\mathrm{t}}$ are the released energy after crack propagation and are therefore represented by the area under the cohesive stress-separation curve. $\Delta \mathrm{u}_{\mathrm{n}}{ }^{*}$ is the value of $\Delta \mathrm{u}_{\mathrm{n}}$ after complete shear separation in absence of normal tension.

Fig. 2: Cohesive law curves

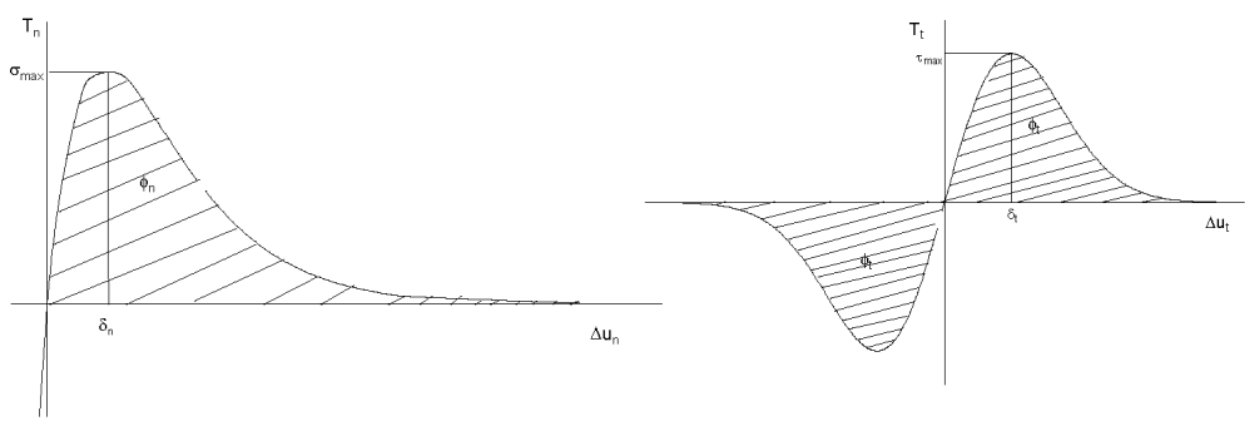

Fig. 3: description of $3 D$ cohesive zone model
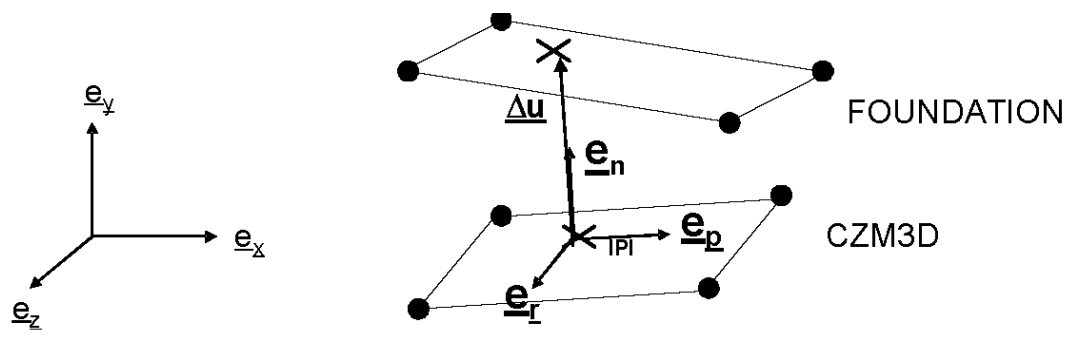


\section{Implementation in Lagamine code}

The cohesive zone is composed of two interface elements of 4 nodes: a foundation and CZM3D (cf. Fig. 3). The CZM3D contains one, four or nine integration points. From the velocity field, the components of the separation distance $\left(\Delta \mathrm{u}_{\mathrm{p}}, \Delta \mathrm{u}_{\mathrm{r}}, \Delta \mathrm{u}_{\mathrm{n}}\right)$ are determined in the local axes $\left\{\underline{\mathrm{e}}_{\mathrm{p}} \underline{\mathrm{e}}_{\underline{\mathrm{r}}} \underline{\mathrm{e}}_{\mathrm{n}}\right\}$ of CZM3D at each integration point. $\Delta \mathrm{u}_{\mathrm{p}}$ and $\Delta \mathrm{u}_{\mathrm{r}}$ describe the shear crack modes (II and III). A shear crack norm $\Delta \mathrm{u}_{\mathrm{t}}$ is computed by equation (4):

$$
\Delta u_{t}=\sqrt{\Delta u_{r}^{2}+\Delta u_{p}^{2}}
$$

The cohesive stresses $\left(T_{n}\right.$ and $\left.T_{t}\right)$ are calculated by equations (1) and (2). Then the cohesive shear stress, $T_{t}$, is projected on the local axes to obtain the components of the shear stresses $\left(T_{r}\right.$ and $\left.T_{p}\right)$ by equation (5).

$$
\underline{\sigma}^{\prime}=\left\{\begin{array}{c}
T_{p} \\
T_{r} \\
T_{n}
\end{array}\right\}=\left\{\begin{array}{l}
\frac{\Delta u_{p}}{\sqrt{\Delta u_{p}^{2}+\Delta u_{r}^{2}}} T_{t} \\
\frac{\Delta u_{r}}{\sqrt{\Delta u_{p}^{2}+\Delta u_{r}^{2}}} T_{t} \\
T_{n}
\end{array}\right\}
$$

Hence $\underline{\sigma}^{1}$ is the cohesive stress vector in the local axis.

\section{Crack test modelling}

An inverse method is used to determine the cohesive parameters from the modelling of a standard CTOD [8] test performed by Corns. A fatigue precracked 355 steel specimen is loaded up to fracture in a three points bending test. The applied force is plotted against the opening displacement V (cf. Fig. 4). In a first step, the model is a two dimensional one [3]. Bulk material is modelled by four nodes mixed BLZ2D [9] elements. The constitutive law is elastoplastic with Von Mises' criterion and isotropic hardening. The three rollers are simulated by circular foundations which are in contact with CNTCP contact elements [10]. The cohesive elements are located in the middle of the specimen, where the stress is maximum. The shear crack mode is neglected. Corns determined experimentally the critical Rice integral, $\mathrm{J}_{\mathrm{IC}}$ [ 11 ] - The cohesive energy is assumed to be equal to this integral. The maximal cohesive stress is varied until equivalent force-displacement plot for the model and the test is obtained. The corresponding characteristic values are: $\sigma_{\max }=2100 \mathrm{MPa}$ and $\delta_{\max }=0.159 \mu \mathrm{m}$.

Fig. 4 shows the $\sigma_{\mathrm{xx}}$ stress. The highest tensions are concentrated around the crack tip and are equivalent to the ultimate tensile stress (540 MPa). The comparison of the experimental and numerical force-displacement curve is available in Fig. 5. The global shape is similar but discrepancies are however evidenced. It has been checked that the mesh density is sufficient by comparing the result of two different meshes with 1000 and 2000 elements. Two types of finite element have been compared (PLXLS [12] and BLZ2D) and provide identical results. The elastoplastic model was identified on only one tensile test. Either the heterogeneity of the material or some difference between the actual and numerical geometry can explain the difference. The use of a plane strain state assumption is another possible reason. Both the three dimensional model and additional experimental tests should provide a better understanding of the results. In a near future, Corus intends to perform several tests and to plot the J-integral as a function of the crack length. 
Fig. 4: $\sigma_{x x}$ stress distribution
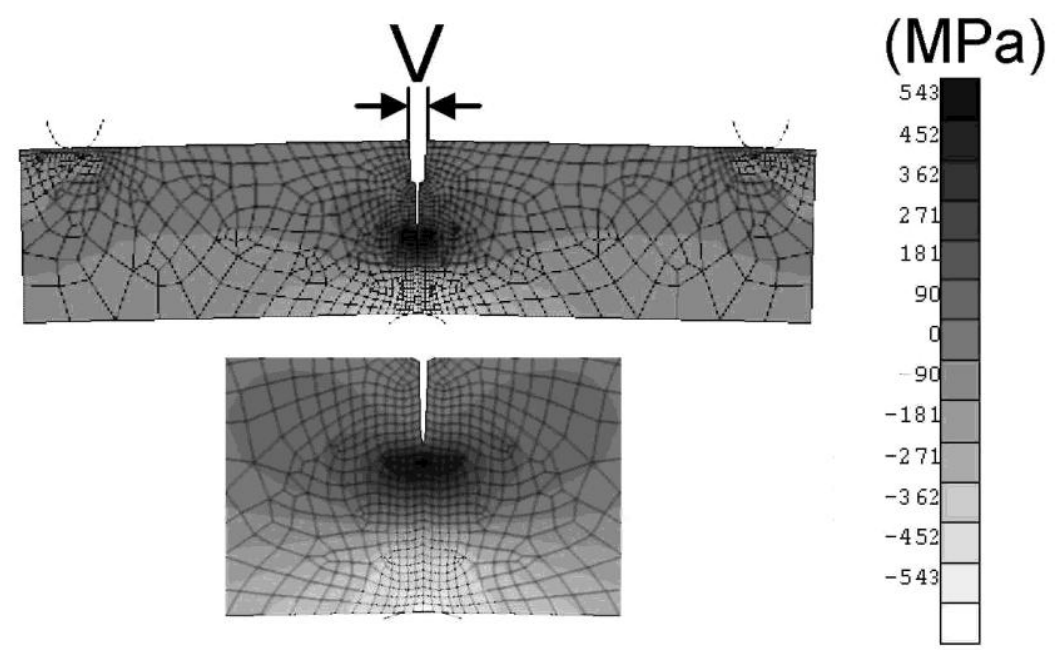

Fig. 5: Force-notch opening displacement curve

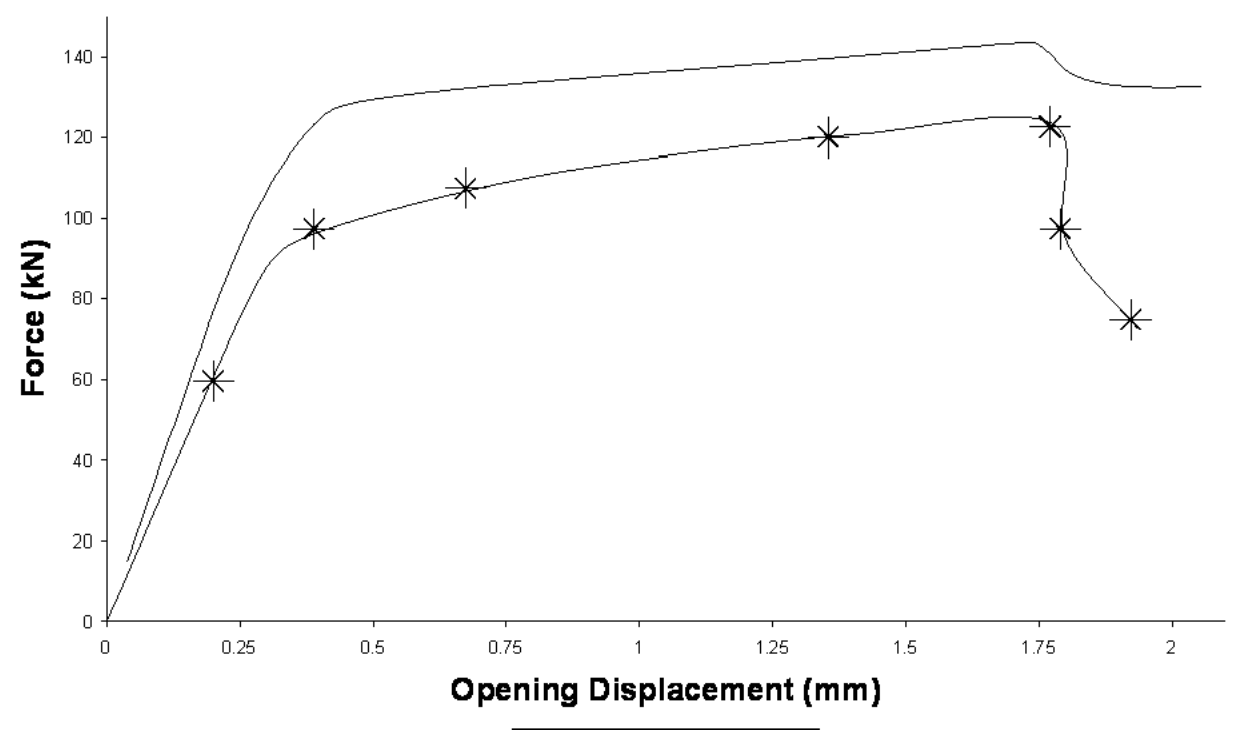

\section{Discussion}

A three-dimensional cohesive zone element has been developed and implemented. It may be used on for a three dimensional finite element simulation of a cyclic test on beam-to-column connection. The method to determine cohesive parameters is ready. The cohesive parameters will be determined for the weld material, the base metal and the heat affected zone composing the connection. The force-displacement curve and the J-integral-crack length curve obtained during a three points bending test, will be fitted between the experiments and the simulation. It is important to notice that the residual stresses generated by the welding are important parameters for the crack toughness. They will be computed by a thermo mechanical analysis which models the welding process. The cohesive zone model will be coupled with the fatigue continuum damage mechanics of Lemaitre and Chaboche [2]. The main problem of the cohesive zone model is that the crack path must ever be known. This path will be assumed in the area where the fatigue damage is maximum. 


\section{Acknowledgments}

This work was performed thanks to the supply of the European Community (VERAPS project $\mathrm{n}^{\circ}$ RFS-CR03035) and the assistance of the project partners (Corus, ISQ, Karlsruhe University). Anne-Marie Habraken and Hervé Degée (research associate) thanks the FNRS.

\section{References}

[1] Y.Y. Zhu, S. Cescotto, A.M. Habraken, Modelling of Fracture Initiation in Metal forming Processes, "Materials Processing Defects" S.K. Ghosh and A. Predeleanu, Elsevier Science, 1995.

[2] J. Lemaitre, J.L. Chaboche, Mécanique des Matériaux Solides, Dunod, édition 2, 1996.

[3] S. A. Mahin, Lessons from damage steel buildings during the Northridge earthquake, Engineering Structures, vol. 20, 1998, pp. 261-270.

[4] C. Lequesne, A.F. Gerday, A. Plumier, A.M. Habraken, Modeling Of The Fatigue Cracks in Welded Beam-To-Column Connection of Steel Moment Frame Buildings Submitted to Earthquake, Advances in fracture and Damage Mechanics IV, ECltd, 2005

[5] G.I. Barenblatt, Mathematical Theory of Equilibrium Cracks, Advances in applied Mechanics, Academic Press, New York, 1962, pp. 55125 .

[6] D.S. Dugdale, Yielding of Steel Sheets Containing Slitls, J. Mech Phys Solids, vol. 8, 1962, pp. 100-104

[7] X.P. Xu, A. Needleman, Void nucleation by inclusion debonding in a crystal matrices, Materials Science and Engineering, A129, 1993, pp. 111-132.

[8] British Standard 7448-1:1991, prepared under the direction of the Iron Steel and the Non-ferrous metals Standards policy Committees, 2004

[9] Y. Zhu and S. Cescotto, Unified and mixed formulation of the 4-node quadrilateral element by assumed strain method: Application to thermomechanical problems, International Journal for Numerical Method in Engineering, vol. 38, 1995, pp. 685-716.

[10] S. Cescotto, A.M. Habraken, Contact between Deformable Solids the Fully Coupled Approach, Special Issue of J. of Mathematical and Computer Modelling, 1996.

[11] J.R Rice, A path independent integral and the approximate analysis of strain concentration by notches and cracks, J. Appl. Mech., 1968, pp. 379-386.

[12] S. Cescotto Essais de qualification de différents elements, Simulation numérique du laminage en cannelures, Rapport semestriel n ${ }^{\circ} 3$, Chapitre II, M.\&S, Université de Liège, 1983. 